\title{
Mapeamento da cana-de-açúcar na mesorregião do Triângulo Mineiro/Alto Paranaíba-MG (2008/2009; 2010/2011)
}

\author{
Laís Naiara Gonçalves dos Reis \\ Mestranda em Geografia, IG-UFU, Bolsista Capes \\ Jorge Luís Silva Brito \\ Professor Dr. adjunto do IG/UFU
}

Resumo: A dinâmica espacial reflete feições características de diversos fatores (econômicos e políticos). O mapeamento da cana-de-açúcar auxilia compreender a territorialização dessa cultura e permite que profissionais planejem o ambiente buscando uma interação entre o social, ambiental e 0 econômico. Como resultado do mapeamento da mesorregião de 2008 para 2010, foi possivel diagnosticar que houve um aumento de $15 \%$ da área plantada de cana-de-açúcar na área de estudo.

Palavras-chave: Sensoriamento Remoto; Cana-de-açúcar; mapeamento.

Abstract: The spatial dynamics reflects characteristic features of many factors (economic and political). The mapping of sugar cane helps to understand the territorialization of culture and allows professionals to plan the environment looking for an interaction between social, environmental and economic issues. As a result of the mapping of the middle region from 2008 to 2010, it was possible to diagnose that there was an increase of $15 \%$ of the area planted with sugar cane in the study area.

Keywords: Remote Sensing; cane sugar; mapping.

\section{Introdução}

Discussões sobre o desenvolvimento sustentável embasam um modelo de modificação energética do país. Para tal, a alternativa para diminuir a dependência dos combustíveis fósseis é a produção dos ditos bicombustíveis ou agrocombustíveis. Para a realidade brasileira, utiliza-se a cana-de-açúcar para a produção dos mesmos.

A estimativa da produção da cana-de-açúcar (2010/2011) no Brasil é de 8033 mil ha, houve um aumento de $137 \%$ em relação à produção da safra 2005/2006 que foi de aproximadamente 5804 mil há. Esse contexto reflete mudanças na configuração sócio espacial em virtude dos interesses do setor sulcroalcooleiro.(UDOP, 2011)

Essa pesquisa utiliza-se das geotecnologias para espacializar os dados das safras da cana-de-açúcar $(2008 / 2009 ; 2010 / 2011)$ na mesorregião do Triângulo Mineiro/Alto Paranaíba, no sentido de compreender a distribuição geográfica da 
cultura bem como verificar que a tendência de crescimento na região é semelhante à condição do cenário nacional.

\subsection{Caracterização da cultura da Cana-de-açúcar}

Novos estudos taxonômicos segundo Cronquist (1981) apud Miranda et AL, 2010. p. 47, mostram que a cana-de-açúcar era conhecida como membro da família das gramíneas pela classificação de Engler (1987) apud Miranda et AL, 2010. p. 47, passa a ser um representante da família Poaceae. (quadro 01)

Quadro 01. Classificação taxonômica antiga e atual da cana-de-açúcar

\begin{tabular}{lll}
\hline Especificação & Engler (1987) & Cronquist (1981) \\
\hline Divisão & Angiospermae & Magnoliophyta \\
Classe & Monocotyledoneae & Liliopsida \\
Ordem & Glumiflorae & Cyperales \\
Família & Andropogoneae & Andropogoneae \\
Tribo & Saccharininae & Saccharininae \\
Subtribo & Saccharum & Saccharum \\
Genêro & Saccharum officinarum & Saccharum officinarum \\
Espécies & Saccharum barberi & Saccharum barberi \\
& Saccharum robustum & Saccharum robustum \\
& Saccharum spontaneum & Saccharum spontaneum \\
& Saccharum sinensis & Saccharum sinensis \\
& Saccharum edule & Saccharum edule \\
\hline
\end{tabular}

Fonte: MIRANDA et AL, 2010. p. 47

A cana-de-açúcar foi cultivada, tradicionalmente, entre as latitudes $35^{\circ} \mathrm{N}$ e $35^{\circ}$ $\mathrm{S}$. Para atender os programas de energia renovável, o manejo varietal da canade-açúcar e estratégia para alcançar diversos ambientes e aumentar a produtividade da cultura. Alguns estudos indicam que o potencial biológico de produção da cana-de-açúcar é de aproximadamente 350 t há -1 de colmos num período de 360 dais (Landell et al. 2005 apud Miranda et al, 2010 p. 139.)

Segundo Tauconnier e Bassereau (1975) apud Miranda, et al. 2010, p. 205, o desenvolvimento da cana-de-açúcar está ligado a temperatura do ambiente. Temperaturas abaixo dos $25^{\circ} \mathrm{C}$, fazem com que a cultura cresça lentamente, temperaturas entre 30 e $34^{\circ} \mathrm{C}$ é ideal, e acima de $35^{\circ} \mathrm{C}$ torna-se lento e superior a uma temperatura de $38^{\circ} \mathrm{C}$ é praticamente nulo e estaciona quando é inferior a $21^{\circ} \mathrm{C}$.

Essa cultura suporta razoavelmente temperaturas elevadas de 34-35 ${ }^{\circ} \mathrm{C}$. No entanto, valores constantes e acima de 38?C podem afetar 0 seu desenvolvimento pelo efeito inibitório e atividades fisiológicas, como abertura de estômatos e troca de $\mathrm{CO} 2$. Contudo esta cultura não é muito tolerante ao frio, sendo que as partes jovens e menos protegidas da cana (folhas jovens e gema apical e gemas laterais jovens) se congelam quando a temperatura se torna inferior a $0^{\circ} \mathrm{C}$. MIRANDA, et al, 2010, p. 205.

Existem basicamente dois tipos de colheita da cana: manual e mecanizada (SOUZA et al., 2005, sp.). A queima da palha pode ocorrer nos dois tipos de colheita, mas também pode-se colher a "cana crua". "Entretanto, a colheita 
manual, quando feita sem o uso do fogo, é difícil de ser executada, uma vez que a queima da palha serve tanto para limpar o local, eliminando a grande biomassa de folhas, quanto para afugentar os animais peçonhentos." (MELLO, 2009, p. 30). Por meio da colheita mecanizada não é necessário a queimada da lavoura, porém é preciso atender algumas condições de relevo, como: inclinação do terreno menor que $12 \%$.

A cana-de-açúcar se desenvolve formando touceiras, constituídas por partes aéreas (colmos e folhas) e outras partes subterrâneas (rizona e raízes). Essa se desenvolve melhor em solos profundos, argilosos de boa fertilidade, e que possuem boa capacidade de retenção de água, não sujeitos a encharcamento, com ph entre 6.0 e 6.5. Para o plantio há necessidade de se fazer uma calagem para que o ph atinja estes valores. Deve-se arar a terra e gradear para fazer os sulcos de plantio com espaçamento de 1 a 1,35 metro entre as linhas. No sulcamento, o solo é adubado simultaneamente. No fundo do sulco são depositados os colmos cortados normalmente e recobertos com terra que darão origem a uma nova planta. (UDOP, 2010, sp.) A cana-de-açúcar produz durante quatro ou cinco anos seguidos, quando diagnostica que a produtividade diminui é feita a reforma do canavial. A canade-açúcar de primeiro corte é chamada de "cana planta", a de segundo corte "cana soca" e de terceiro corte em diante "ressoca". O plantio efetuado no período de fevereiro a maio produz a cana-de-açúcar de "ano e meio" e o efetuado no período de outubro a dezembro, a "cana de ano". (UDOP, 2010, sp.)

Segundo Rudorff et al. (2004), o calendário agrícola (quadro 02) da cana-deaçúcar na região sudeste pode ser descrito da seguinte maneira:

(...) o termo $A$ (cana de ano) corresponde à cana cujo plantio vai de agosto a outubro, quando se inicia o período das precipitações de primavera. As variedades de cana de ano exigem solos mais férteis e devem estar prontas para a colheita do meio para o fim da safra; já o termo $A M$ (cana de ano e meio) corresponde à cana plantada entre outubro a abril. Normalmente essa modalidade possui boa produtividade, com tempo de crescimento de 15 a 18 meses e variedades precoces, médias e tardias. (MELLO, 2009, p. 31)

Quadro 1. Calendário agrícola da cana-de-açúcar.

\begin{tabular}{|l|l|l|l|l|l|l|l|l|l|l|l|l|}
\hline Fase & Jan & Fev & Mar & Abr & Mai & Jun & Jul & Ago & Set & Out & Nov & Dez \\
\hline Plantio & AM & AM & AM & AM & & & & A & A & AM & AM & AM \\
\hline Colheita & & & & & & & & & & & & \\
\hline
\end{tabular}

Legenda: AM- Cana-de-açúcar de ano e meio / A- Cana-de-açúcar de ano.

Fonte: Adaptada de MELLO, M. P, p. 31

Conforme indica o calendário agrícola da cana-de-açúcar o período entre safra dessa cultura ocorre nos meses de dezembro á março.

As safras da cana-de-açúcar podem ser de inverno ou de primavera. A colheita no período de inverno pode trazer prejuízos às socas, efeito esse que pode ser minimizado com o emprego da vinhaça e/ou irrigação. Já as safras de 
primavera correspondem ao período de outubro e novembro. É de fundamental importância o uso de cultivares com capacidade superior de brotação ou perfilhamento, para garantir a longevidade dos canaviais. (MIRANDA et al, 2010 p. 142)

O número de cortes de um canavial está diretamente ligado com a fertilidade do solo. Quanto maior a fertilidade, maior o número de cortes. A diferença da produtividade do primeiro corte da cana planta é bem maior do que $05^{\circ}, 6^{\circ}$ corte. "No caso da cana-de-açúcar, a manutenção da palhada, aplicações de vinhaça, torta entre outros, possivelmente minimizando esse problema."

Quanto ao uso de defensivos agrícolas, o setor canavieiro utiliza tecnologias que minimizam o uso dos mesmos. Utiliza-se o controle biológico de pragas, como a broca da cana-de-açúcar e a cigarrinha. "O manejo integrado de pragas e as boas praticas agrícolas que evitam derivas e aplicações próximas as áreas de preservação ambiental devem ser implementadas e fiscalizadas." (MIRANDA et al, 2010. p. 877)

\section{2 Áreas de Estudo}

A área de estudo do trabalho foi a mesorregião do Triângulo Mineiro / Alto Paranaíba localizada a oeste do Estado de Minas Gerais, sendo composta por 66 municípios (figuras 01), ocupando uma área de $90.545 \mathrm{~km}^{2}$, equivalente a $15,4 \%$ do território mineiro. (IBGE, 2010) havia uma população de 2.176.060 habitantes em 2009. O relevo da região está inserido na grande área denominada Chapadões Tropicais do Brasil Central. (AB'SABER, 1971). Quanto à geologia a mesma situa-se a Formação Serra Geral.

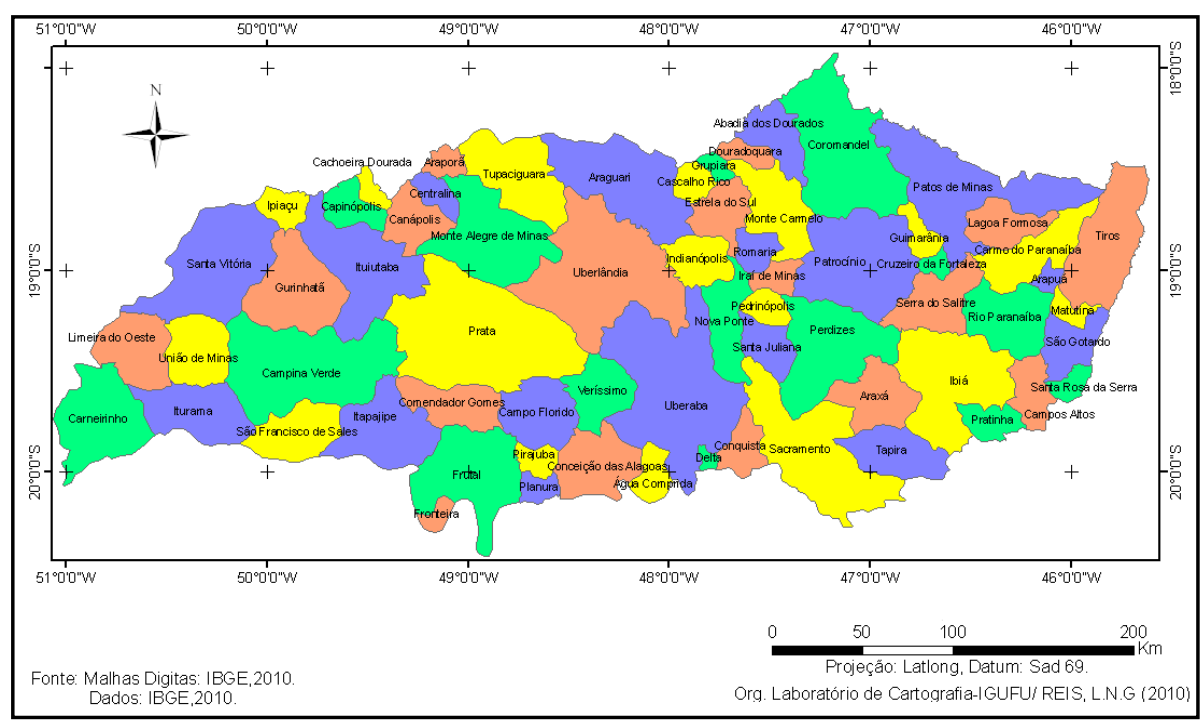

Figura 1. Municípios da Mesorregião do Triângulo Mineiro/Alto Paranaíba - MG.

O Triângulo Mineiro/Alto Paranaíba está inserido no Bioma Cerrado ou savânico. As savanas são formações que ocorrem no clima tropical e subtropical. Essas constituem um extrato de gramíneas, havendo interrupções por arvores e arbustos. As matas ciliares desse bioma estão longo dos rios e constituem-se em um refúgio e corredores de dispersão de espécies das florestas tropicais úmidas (Amazônia e Atlântica). As veredas se constituem em cabeceiras de drenagem, comportando afloramento do lençol freático 
comportando solos hidromórficos com altos teores de matéria orgânica (ROSOLEN, 2006).

O clima da mesorregião do Triângulo Mineiro/ Alto Paranaíba tem como característica principal uma alternância de duas estações bem definidas ao longo do ano: uma estação chuvosa e outra seca, com duração de cerca de seis meses cada. A primeira (chuvosa) tem início no mês de outubro, com término no mês de março e correspondem ao período de maiores temperaturas médias mensais; já a segunda ocupa o restante do período (abril a setembro) e tem como característica uma diminuição sensível nos índices pluviométricos e com temperaturas mais amenas. As precipitações variam entre 1.300 e 1.700 $\mathrm{mm}$ anuais, com temperatura média anual, variando entre $19 / 20^{\circ} \mathrm{C}$ nas áreas mais elevadas e superando os $24^{\circ} \mathrm{C}$ nas áreas de menor altitude (Baixo Rio Grande e Rio Paranaíba). Outro fator que caracteriza, também, o clima regional, está relacionado com a forte concentração das precipitações nos meses de dezembro e janeiro chegando a responder por $40 \%$ do total anual; nesses meses é comum a ocorrência de fortes chuvas com alta intensidade. Por outro lado, a duração do período de estiagem apresenta-se muito irregular, podendo em alguns anos ocorrer longos períodos de seca, sem ocorrência de nenhuma precipitação, por um período de até 3 meses, não raro, superando 100 dias (ASSUNÇÃO, 2002).

\section{Metodologia de Trabalho}

Para a geração dos mapas de áreas ocupadas com cana-de-açúcar em 2008, utilizou-se o software SPRING 5.1. A base cartográfica da área de estudo foi elaborada a partir das cartas topográficas digitais, escalas 1:100.000 e 1:50.000 no formato digital, disponíveis no sitio do IBGE. Para o trabalho foram utilizadas as imagens TM/Landsat dos anos de setembro 2008 para a mesorregião, bandas 3, 4 e 5 .

O processamento digital das imagens no software SPRING 5.1 foi realizado, utilizando as seguintes etapas:

- Registro: as coordenadas da imagem foram relacionadas com as coordenadas geográficas do mapa base, eliminando prováveis distorções na imagem causadas no processo de formação da imagem pelo sistema sensor ou pela imprecisão dos dados de posicionamento da plataforma. Foi adquirido um conjunto de pontos de controle, resultando num erro de registro (erro quadrático médio) inferior a um pixel. (BRITO et al. 2005);

- Operação de contraste: com o objetivo de melhorar a qualidade da imagem foi realizado um contraste linear, que consiste numa transferência radiométrica nos "pixels" para aumentar a discriminação visual dos objetos presentes na mesma. (BRITO et al. 2005);

- Geração da composição colorida: uma composição colorida, com as bandas TM3 no canal azul, TM4 no canal vermelho e TM5 no canal verde foi gerada. A partir desta composição foi criada uma imagem sintética que possibilitou a 
classificação do uso do solo na área de estudo, utilizando-se o método de interpretação visual de imagens em tela (monitor de vídeo), com escala de visualização de 1:50.000.

Para auxiliar na interpretação das imagens, foi elaborada uma chave de fotointerpretação, onde foram considerados os seguintes elementos de fotointerpretação: textura, cor e forma. (BRITO et al. 2005)

\subsection{Mapeamento das áreas ocupadas com cana de açúcar em 2008/2009}

O mapeamento das áreas ocupadas com cana-de-açúcar em 2008 foi elaborado através da interpretação visual em tela de computador da composição colorida (3B4R5G) utilizando a função de edição vetorial do SPRING 5. 1.

A chave de interpretação das composições coloridas foi construída para orientar a análise das imagens durante o processo de interpretação em tela de computador, sendo consideradas as informações de cor, textura e formas geométricas para 4 categorias da cultura (REIS; BRITO, 2010).

A delimitação dos polígonos das áreas ocupadas com cana-de-açúcar em 2008 na composição colorida $(3 \mathrm{~b} 4 \mathrm{r} 5 \mathrm{~g})$ foi realizada pelo processo de interpretação visual na tela do computador através do software SPRING 5.1, com uma escala de visualização das imagens de 1: 30.000 .

\section{Resultados e Discussões:}

Existem importantes grupos do setor agroindustrial e que detém a produção vertical do processo sucroalcooleiro na região do Triângulo Mineiro Alto Paranaíba, desde o cultivo da cana-de-açúcar até a produção de fontes energéticas (SOUZA, A. G, 2009. pp. 7-9. Como exemplo:

- Grupo Tércio Wanderley: tem usinas em: Iturama, Limeira do Oeste e Campo Florido. Notadamente, a matriz é a unidade de maior produção de açúcar e álcool, e também das regiões Norte e Nordeste;

- Grupo João Lyra: possui a usina Laginha Agro Industrial S.A. - Unidade Triálcool, no município de Canápolis, com sistema multimodal produzindo cerca de 2,0 milhões de sacas de açúcar e 90 milhões de litros de álcool e possui outra unidade, a Usina de refino de açúcar Laginha Agro Industrial S/A - Vale do Paranaíba no município de Capinópolis;

- Grupo Moema: a Usina de Itapagipe Açúcar e Álcool Ltda., do grupo Moema, localiza-se na Fazenda Água Amarela na zona rural do município de Itapagipe;

- Grupo Bunge: usina localizada no município de Santa Juliana, Agroindustrial Santa Juliana foi adquirida em setembro de 2007, pela empresa norte americana Bunge.). 
Devido à existência desses grupos na região pode-se observar a importância da região na produção da cana-de-açúcar, gráfico 01. A relevância do Triângulo Mineiro Alto Paranaíba é principal no setor sucroalcooleiro comparando com os dados do restante das outras mesorregiões do Estado de Minas Gerais, sendo que os dados da produção se tornaram maiores do que a somatória das demais mesorregiões a partir do ano de 2005.

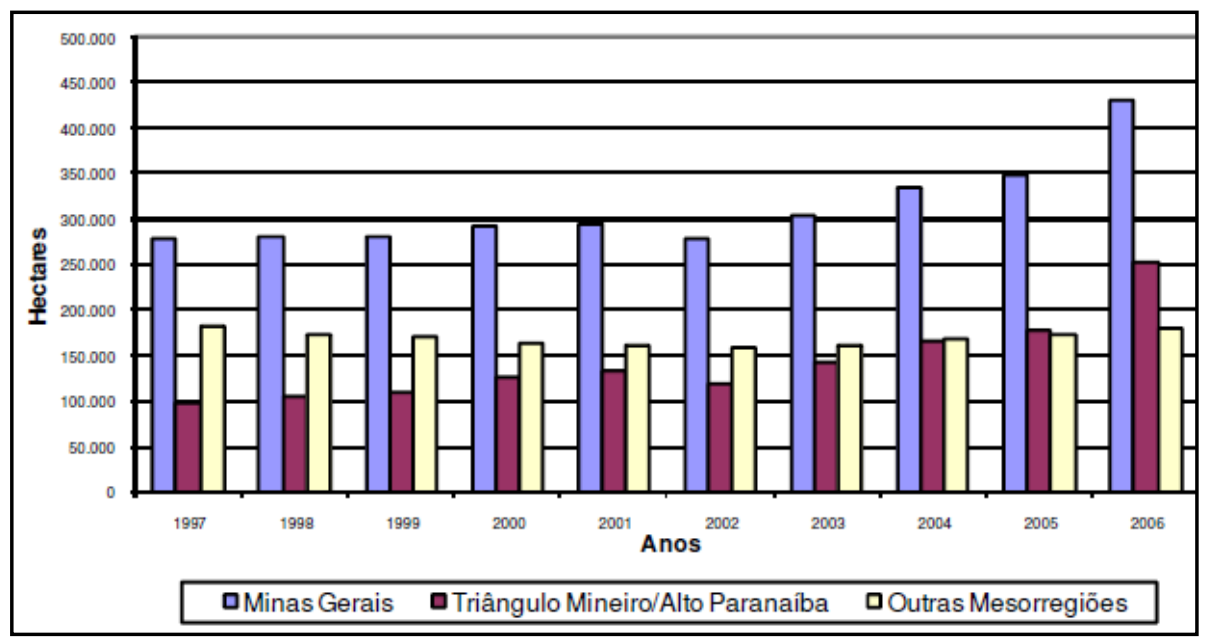

Gráfico 1. Minas Gerais: Comparativo da evolução da área colhida de cana-de-açúcar de 1997 a 2006 (Hectares). Fonte: IBGE, 2008. Org.: CARVALHO, E. R., 2008.

No mapa da figura 02, observa-se a distribuição das usinas sucroalcooleiras pela mesorregião. Existem três usinas que estão em processo de instalação, nos municípios de Uberlândia, Araguari e Comendador Gomes, com previsão de funcionamento para o ano de 2012.

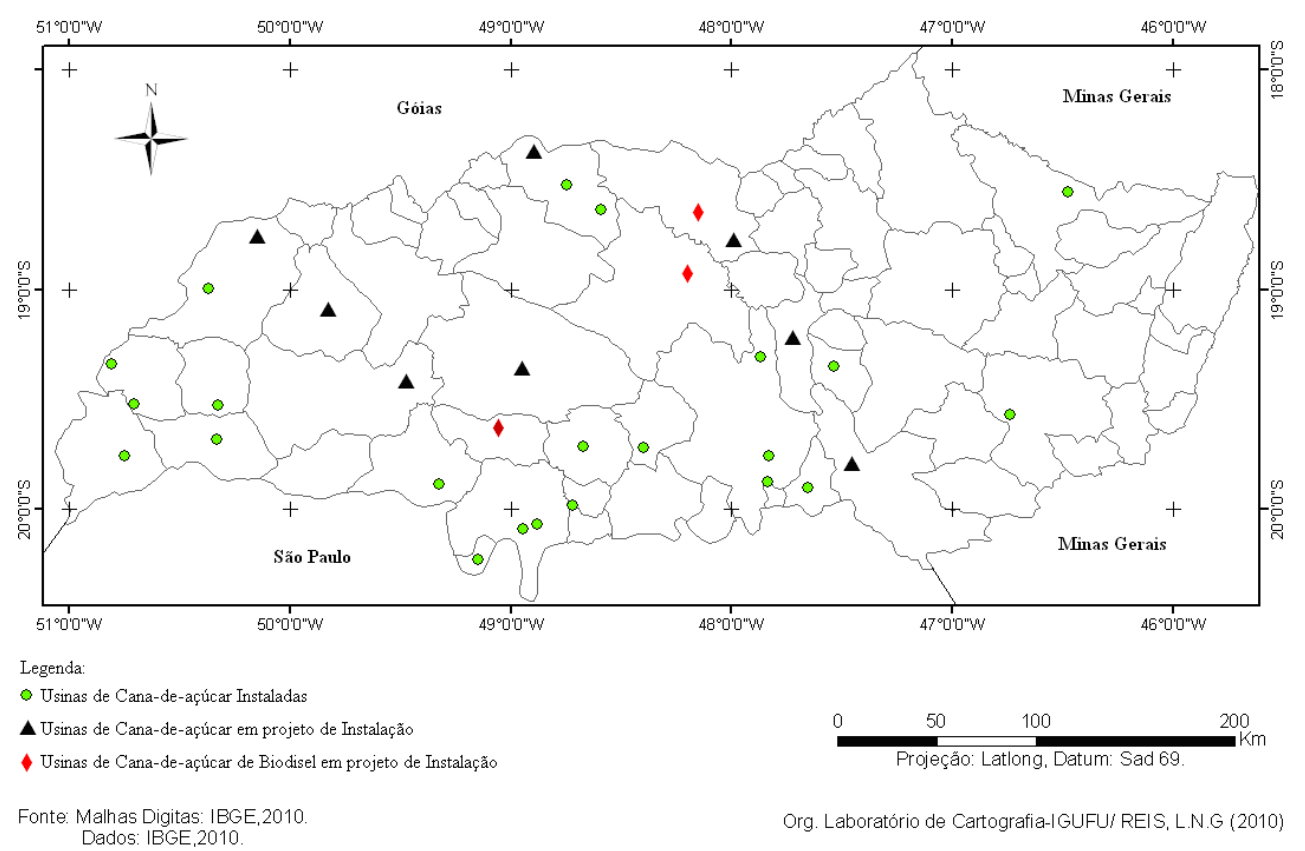

Figura 02. Infraestrutura das Usinas de Cana-de-açúcar instaladas na mesorregião do Triângulo Mineiro/Alto Paranaíba-MG 


\section{REVISTA TAMOIOS}

A área ocupada pela cultura de cana-de-açúcar em 2008/2009 foi de 495.926,4 ha, correspondendo 5,47 \% da área total da Mesorregião do Triângulo Mineiro /Alto Paranaíba, que é de 9.053.365 há. Os municípios que possuem maior concentração dessa cultura em 2008 são: Conceição das Alagoas, Frutal e Uberaba. (Figura 03)

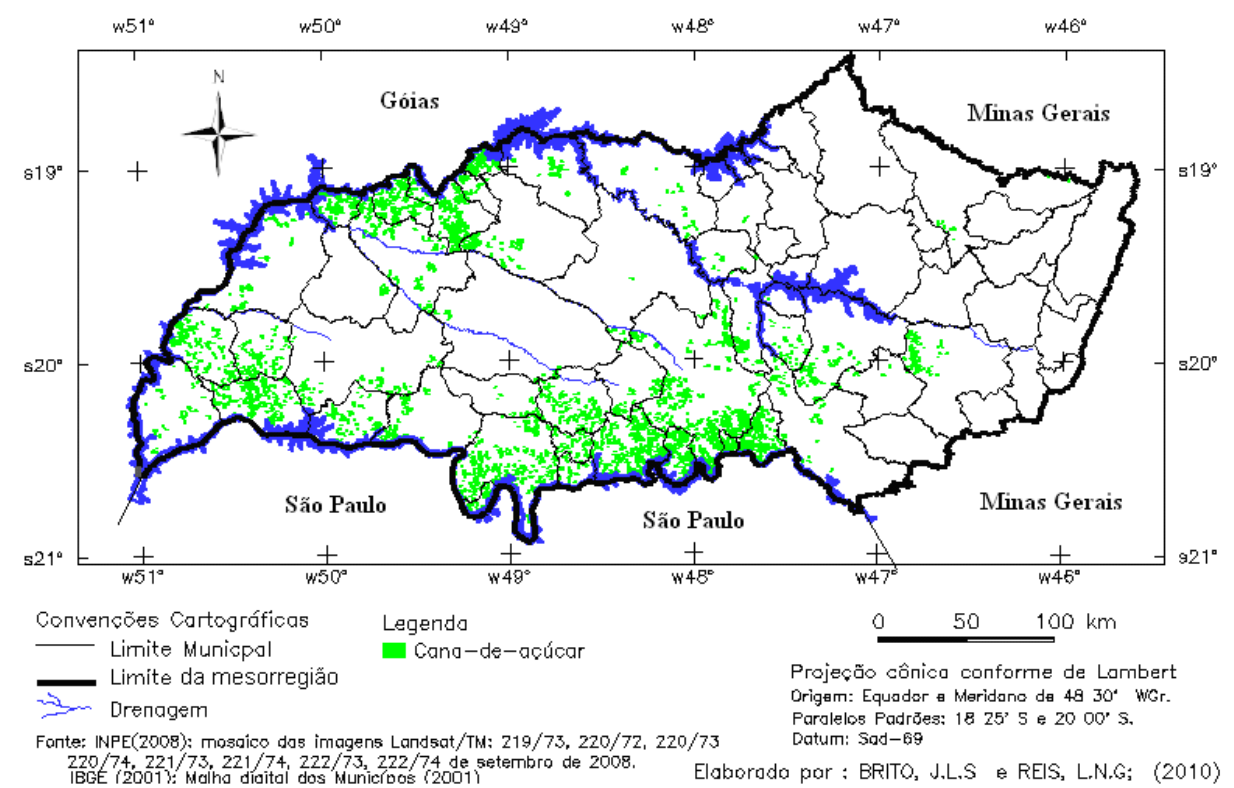

Figura 03. Espacialização da cana-de-açúcar na mesorregião do Triângulo Mineiro/Alto Paranaíba-MG (2008). Org. Reis, L. N. G(2010)

Segundo o Rudorff et al. (2010), a área ocupada pela cana-de-açúcar na mesorregião do Triângulo Mineiro/Alto Paranaíba em 2010/2011 era de 577.074 ha, ou seja, houve um aumento de $15 \%$ em relação aos dados de 2008. As áreas de cana-de-açúcar estão distribuídas geograficamente no mapa da figura 04. 


\section{REVISTA TAMOIOS}

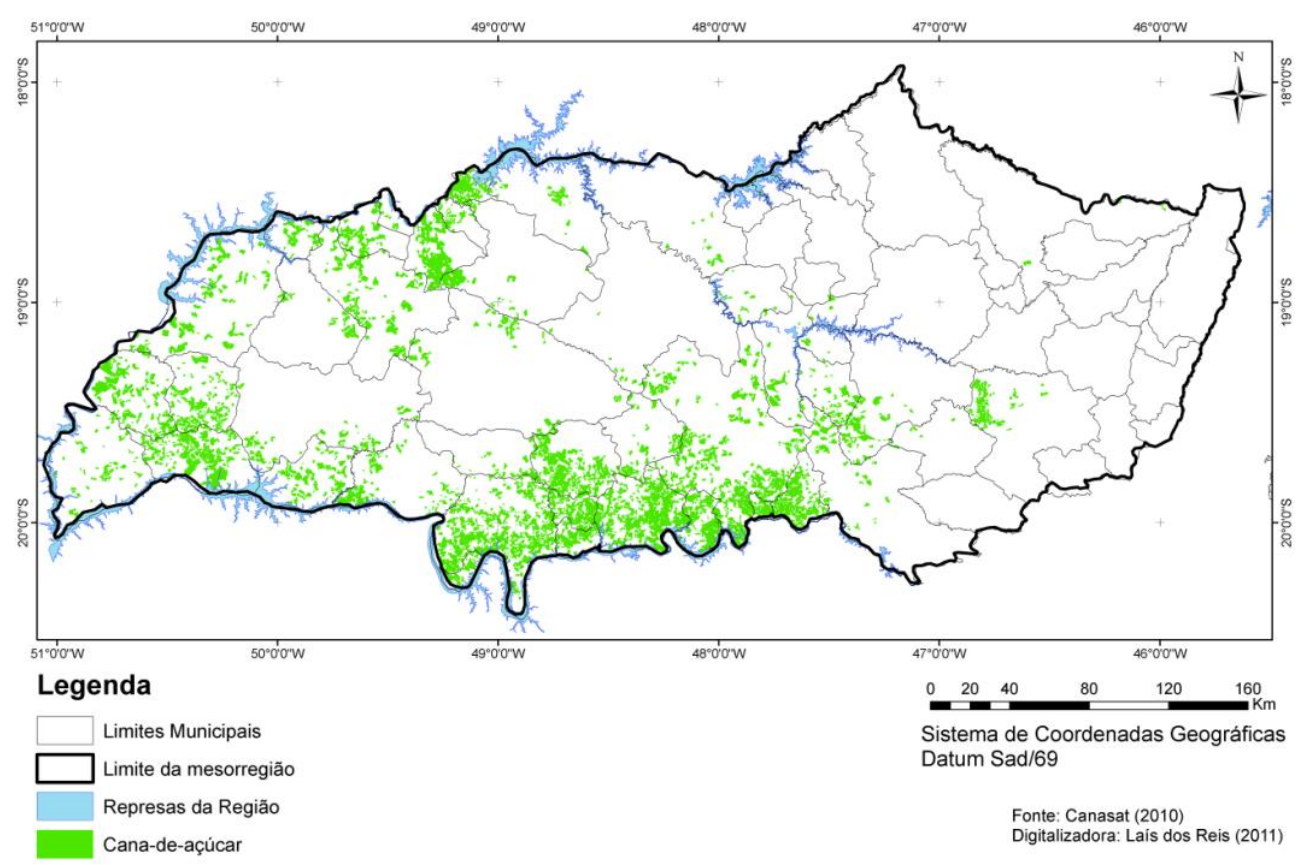

Figura 04. Mapeamento das áreas de cana-de-açúcar da safra 2010/2011

Segundo Campos (2011,p.77), a expansão da cana-de-açúcar na mesorregião do Triângulo Mineiro/Alto Paranaíba-MG, ameaça a produção das seguintes culturas: milho, soja, sorgo, algodão, feijão e arroz. Essa realidade pode ser prevista, conforme o cenário atual de São Paulo:

Como apontado no estudo sobre os impactos de grandes projetos em direitos humanos, a expansão da cana no cerrado pode estar ocorrendo em áreas agrícolas ou remanescentes da vegetação nativa e as regiões que estão sendo afetadas por essa expansão já apresenta grande queda na produção de alimentos, como já ocorreu no Estado de São Paulo, onde a produção de cana, superou a de cultivos como: milho, feijão, café e laranja. (CAMPOS, 2011, p.77-78)

Porém, num mapeamento realizado do uso da terra e cobertura vegetal natural (1999) para as áreas de cana-de-açúcar (2008) elaborado por REIS e BRITO (2012,p.183) mostram que para a realidade da mesorregião do Triângulo Mineiro/Alto Paranaíba-MG, a maioria das novas áreas de expansão da canade-açúcar se deram sobre áreas de pastagem e não de agricultura como é pensado.

Os resultados do mapeamento das áreas de conversão do uso da terra para cana-de-açúcar (2008) (Tabela 03) indicaram que as áreas ocupadas pela cana-de-açúcar passaram de 226482,5 ha (em 1999) para 495926,4 ha (em 2008), correspondendo a um aumento de aproximadamente $119 \%(226482,5)(\ldots)$ a expansão das novas áreas de cana-de-açúcar substituiu, principalmente, as áreas de pastagem, seguida das áreas de agricultura. Já a área de cobertura vegetal natural que foi desmatada para o plantio da cultura referida, nesse intervalo de tempo (1999-2008) corresponde a apenas $1 \%$, ou seja, (2.301,904 ha). (REIS e BRITO, 2012, p. 183-184) 


\section{Conclusões}

A metodologia de mapeamento da cana-de-açúcar por meio de imagens de satélite TM/ Landsat pode ser utilizada para estimar a área dessa cultura, auxiliando a atividade econômica ligada a esse setor.

Como o trabalho utilizou o método de classificação visual em tela, não foi possível realizar o mapeamento multitemporal da cultura, que é importante para compreensão da dinâmica empregada nessas áreas, mesmo assim, os resultados podem ser comparados com órgãos oficiais como IBGE e INPE.

Para um estudo avançado sobre o comportamento da cultura da cana-deaçúcar, recomenda-se empregar um método de classificação supervisionada e fazer o mapeamento de três períodos ao ano.

O mapeamento da cana-de-açúcar na mesorregião do Triângulo Mineiro/Alto Paranaíba contribuiu para um diagnóstico, um primeiro olhar da paisagem buscando conhecer a expansão e a incorporação de novas áreas na região. A escala regional contribui para estudos regionais que buscam caracterizar a dinâmica agroindustrial. Comparado com mapeamentos mais antigos da região, percebe-se uma expansão da cana-de-açúcar ao longo do vale do Rio Araguari.

\section{Agradecimentos:}

Agradecemos á Capes pelo apoio e fomentação a essa pesquisa de Iniciação Científica, ao Instituto de Geografia-UFU que disponibilizou o transporte para o trabalho de campo e os materiais, softwares e equipamentos disponíveis no Laboratório de Cartografia e Sensoriamento Remoto utilizados nessa pesquisa.

\section{Referências Bibliográficas:}

ASSUNÇÃO, W. L. Climatologia da Cafeicultura Irrigada no Município de Araguari (MG). 2002. 266 f. Tese (doutorado) - Faculdade de Ciências e Tecnologia da Universidade Estadual Paulista. Presidente Prudente, 2002.

$A B$ 'SABER, A. N. Contribuição à geomorfologia da área dos Cerrados.

Simpósio sobre o Cerrado. São Paulo, EDUSP, 97-103p., 1971.

BRITO, J.L.S. \& PRUDENTE, T.D. Analise temporal do uso do solo e cobertura vegetal do município de Uberlândia-MG, utilizando imagens ETM+/Landsat7.

Revista Sociedade \& Natureza, Uberlândia, v.17, n.32, 37-46, jun.2005. INSTITUTO BRASILEIRO DE GEOGRAFIA E ESTATÍSTICO-IBGE. Dados sobre a área do município, sócio econômico e da cultura temporária da cana-de-açúcar.

Disponível

em< http://www.ibge.gov.br/cidadesat/topwindow.htm?1> Acessado em 01 de Janeiro de 2009. 
CAMPOS, N.L (2011). Expansão Canavieiras e impactos sócio-ambientais da produção de agrocombustível no Triângulo Mineiro (1980-2011). Disponível em:<

http://www.lagea.ig.ufu.br/biblioteca/monografias/MONOGRAFIA NATALIA LO RENA CAMPOS LAGEA UFU.pdf> Acessado março de 2012.

ROSLEN et al; Expansão dos solos hidromórficos na paisagem sudoeste da bacia amazônica brasileira: mudanças texturais e da porosidade do solo. Disponível em: < http//www.caminhosdegeografia.ig.ufu.br/> Acessado em maio de 2010.

REIS, L.N.G, BRITO, J.L.S (2010). A expansão da cana-de-açúcar na mesorregião do Triângulo Mineir/Alto Parnaíba-MG. Disponível em:< http://www.dsr.inpe.br/sbsr2011/files/p0407.pdf> Acessado em junho de 2010.

REIS, L.N.G, BRITO, J.L.S (2012). Mapeamento das áreas de conversão e uso da terra para cana-de-açúcar na mesorregião do Triângulo Mineiro Alto Paranaíba por meio de imagens Landsat.In: Caminhos de Geografia: ISSN 1678-6343, V. 13, N. 41 (2012).

MIRANDA, L.L.D; et. al. Cana-de-açúcar. Campinas: Instituto Agronômico, 2010. $882 \mathrm{p}$. 